\title{
Perceived Stigma Towards Psychological Illness in Relation to Psychological Distress Among Medical Students in Riyadh, Saudi Arabia
}

\author{
Dalal Ibrahim Alfayez ${ }^{1}$ (D) $\cdot$ Norah Ali AlShehri $^{2}$ \\ Received: 19 October 2019 / Accepted: 7 May 2020 / Published online: 26 May 2020 \\ (C) The Author(s) 2020
}

\begin{abstract}
Objective Due to the high prevalence of psychological distress among medical students and its related functional and cognitive implications, this study aimed to investigate the association between perceived stigma and psychological distress, estimate the prevalence of each level of distress among medical students, and determine the independent significant risk factors of outcome variables for each level of psychological distress.

Methods A cross-sectional study was performed that surveyed medical students at King Saud University in 2018. Using the modified and validated stigma scale for receiving psychological help along with Kessler psychological distress scale, the survey measured perceived stigma towards mental illness in relation to the level of psychological distress.

Results Among the 524 participants, 395 surveys were completed. Participants had a mean age of 21.56 years old, and $53 \%$ were female. The overall prevalence of severe psychological distress was 30.7\% $(N=161)$. Furthermore, $25.6 \%$ of participants reported experiencing moderate distress $(N=134)$. Additionally, a significant association was found between females and severe psychological distress. Moreover, family income was significantly associated with severe psychological distress in the extreme lower and upper groups (5000-10,000 SR and above 20,000 SR). Participants with high levels of psychological distress were more likely than those with low levels to agree or strongly agree with 3 out of 10 items related to perceived stigma.

Conclusions Medical students with moderate/severe psychological distress disclosed more concerns regarding stigma, particularly about perceived consequences of their mental health issues being revealed to others. Such opinions could cause physical health problems and decrease quality of life.
\end{abstract}

Keywords Medical students $\cdot$ Psychological distress $\cdot$ Stigma

Psychological distress poses a substantial public health concern that affects people all around the world. The term psychological distress has been defined as a state of emotional suffering characterized by symptoms of depression and anxiety that are sometimes accompanied by somatic symptoms (e.g., insomnia, headaches, lack of energy) [1, 2]. Such suffering can have a tremendous effect on an individual, both directly and indirectly. Psychological distress has been shown to cause cognitive impairment and physical health issues such

Dalal Ibrahim Alfayez

alfayez.d@gmail.com

1 King Saud University Medical City, Riyadh, Saudi Arabia

2 King Saud University, Riyadh, Saudi Arabia as arthritis, cardiovascular disease, and chronic obstructive pulmonary disease $[3,4]$.

Medical students in particular were found to experience great levels of stress during their academic years $[5,6]$. Such distress may influence their concentration, learning, and ability to memorize information well, which subsequently affects their educational achievement and later careers.

Due to the wide range of scales used to assess psychological distress, no single value can be specified regarding its global prevalence; however, its prevalence approximately ranges between $5 \%$ and $27 \%$ in the general population [7-9]. Furthermore, it has been observed that medical students also suffer from high levels of psychological distress, regardless of their medical knowledge. For example, in 2017, Al Saadi showed that $52.6 \%$ of Syrian medical students at Damascus University suffered from psychological distress [10]. Additionally, in 2007, Dyrbye found that 49\% of 1701 
medical students from five different universities in the USA had depressive symptoms [11].

In Saudi Arabia, epidemiological data on psychological disorders among the general population are scarce. However, studies have been conducted on psychological distress in particular populations and age groups. Multiple local studies have been conducted to estimate the prevalence of psychological distress and depressive symptoms among medical students $[12,13]$. About $64 \%$ of King Saud University medical students reported having psychological distress during the 2007-2008 academic year [12]. In addition, $46.2 \%$ of King Saud University medical students reported having depressive symptoms in 2012-2013 [13].

In most studies, two characteristics were found to be worthy of attention: gender and age; the prevalence of psychological distress has been found to be higher among females of all age groups [14-17] than males in the USA, Australia, Syria, and Saudi Arabia $[1,18,19]$. Furthermore, it was previously observed that the prevalence of psychological distress tends to decrease in late adolescence and early adulthood age groups $[1,8,18,20]$.

Due to the alarmingly high prevalence of psychological distress and depressive symptoms among medical students $[12,13]$, early recognition and treatment are important to provide effective management and avoid adverse negative outcomes. However, none of these local studies addressed the effects of perceived stigma on mental illnesses, which may lead to self-neglect and subsequent underdiagnoses and lack of treatment, particularly among medical students.

Additionally, one of the major barriers to self-awareness regarding psychological disorders is perceived stigma by either the public or the patients themselves. Stigma has been described as "a cluster of negative attitudes and beliefs that motivate the general public to fear, reject, avoid, and discriminate against people with mental disorders" [21]. Considerable researches affirm stigma to be recognized as a barrier to recovery; stereotypes, prejudice, and discrimination against mentally ill patients will affect person's sense of self and consequently withhold seeking for help and adhering to ongoing treatment [22].

The objectives of the current study were as follows: to examine the association between perceived stigma and psychological distress, estimate the prevalence of each level of psychological distress among medical students, and determine the independent significant risk factors for all outcome variables (e.g., GPA, year of study, gender, and age) of each level of psychological distress.

\section{Methods}

This study used a cross-sectional design to explore perceived stigma in relation to the level of psychological distress among medical students, conducted in 2018-2019. The institutional review board at King Saud University approved the study prior to the recruitment of participants. All participants were current medical students at King Saud University from all five academic years. Students were invited via e-mail through the student council to participate in the study by voluntary completing an online survey. Out of 1500 medical students, 525 agreed to participate in the study (35\%) and 395 completed the survey $(26.3 \%)$; responses were anonymized by using electronic survey with non-identifying questions. Completed questionnaires were collected 2 months before the university's examination period so that actual examination stress would not affect the students' responses.

\section{Study Measures}

The survey included sociodemographic items (age, gender, academic year, GPA, marital status, and family income), standard instruments to measure dimensions of psychological distress (Kessler psychological distress scale) [23], and items exploring perceived stigma regarding mental illness [24].

\section{Psychological Distress}

The six-item Kessler psychological distress scale (K6) is the most widely used screening scale of non-specific psychological distress providing an estimate prediction of the prevalence of serious mental illness, defined as meeting diagnostic criteria for a DSM-IV disorder in the past 12 months and experiencing significant impairment with sensitivity in the upper 90th-99th percentile range [25]. The validity of this scale is well-established internationally including in populations of medical students, higher K6 scores were reported by individuals receiving one or more mental health treatment [26]. Frequency of feeling nervous, hopeless, restless, or fidgety, so sad that nothing could cheer them up and that everything was an effort and worthless, were assessed and graded. Each item is scaled from zero to four, with zero meaning "none of the time" and four meaning "all of the time." Total scores range between 0 and 24, and are further divided into three categories: scores between 13 and 24 represent high psychological distress; scores between 8 and 12 indicate moderate psychological distress; and scores between 0 and 7 represent low psychological distress [23]. Participants who had high scores representing moderate to severe psychological distress could not be reached individually due to the anonymous nature of the survey; therefore, an official e-mail was sent through the student council to all students thanking them for their participation along with providing guidance for accessing school-specific mental health resources. 
Stigma

Stigma involves multiple dimensions, including social stigma and self-stigma. Validated scales measuring stigma for receiving professional psychological help assessing these dimensions $[22,27]$ were previously selected and modified by other researches to be more relevant to medical students [24]. Liselotte N. Dyrbye, the author of "The Impact of Stigma and Personal Experiences on the Help-Seeking Behaviors of Medical Students with Burnout," was contacted via e-mail and granted her permission to use and print the survey [24]. The questionnaire consists of 10 questions regarding the dimensions of stigma. Self-stigma refers to medical students thinking it is a sign of personal weakness or inadequacy to receive treatment for emotional or mental health problems. Social stigma focuses on the individuals around medical students, including residency directors, supervisors (e.g., faculty, residents, deans), fellow students, and patients, and how these individuals would view the students if they were aware they had received treatment for an emotional or mental health problem. Additionally, the questionnaire includes questions regarding the confidentiality of medical students, if they were to receive mental health treatment.

\section{Analysis}

Based on previous literature, the use of the most conservative choice with $p=0.5$. To ensure the estimation error would be at most alpha 0.05 with $95 \%$ confidence, a sample size of 416 was required with assumption of $10 \%$ non-response. Categorical data were summarized with absolute numbers and percentages. Numeric data were summarized with mean and standard deviation (SD). Comparisons between different groups were performed using Chi-square test or Fisher exact test for categorical variables. Multiple logistic regression models were used to identify independent risk factors for stress. To quantify multivariate association, odds ratio with $95 \%$ confidence intervals (CI) was estimated. All the analysis was performed using the [SAS/STAT] software, version [9.2] (SAS Institute Inc., Cary, NC, USA.). A 2-sided $p$ value < 0.05 was considered statistically significant.

\section{Results}

\section{Sociodemographic Data}

Out of 1500 medical students, 524 responded to the online survey. From that group, 395 surveys were completed, for a completion rate of $26.3 \%$. Table 1 describes demographic characteristics of the participants. Participants had a mean age of 21.56 (SD 1.68), and more than half were female $(253 ; 53 \%)$. The majority were in their fourth year of medical
Table 1 Characteristics of study subjects

\begin{tabular}{llll}
\hline Variable & Level & $N=524$ & Percent \\
\hline Age & Mean & 21.56 & - \\
Gender & SD & 1.68 & - \\
& Male & 219.00 & 46.4 \\
Year & Female & 253.00 & 53.6 \\
& 1st & 82.00 & 17.4 \\
& 2nd & 93.00 & 19.7 \\
& 3rd & 101.00 & 21.4 \\
& 4 th & 110.00 & 23.3 \\
Marital status & 5th & 86.00 & 18.2 \\
& Single & 455.00 & 96.4 \\
Family income & Married & 13.00 & 2.8 \\
& Divorced & 4.00 & 0.8 \\
& $<5000$ SR & 22.00 & 4.7 \\
& $5000-10000$ SR & 46.00 & 9.7 \\
& $>10000-20000$ SR & 133.00 & 28.2 \\
GPA & $>20000$ & 271.00 & 57.4 \\
& $4.75-5$ & 114.00 & 24.8 \\
& $4-4.74$ & 252.00 & 54.8 \\
& $\leq 3.99$ & 94.00 & 20.4 \\
\hline
\end{tabular}

school $(110 ; 23.3 \%)$, single $(455 ; 96 \%)$, and had a high family income exceeding 20,000 Saudi Riyals (271; 57.4\%). More than half of the students had good cumulative grade point averages, ranging from 4-4.74 out of 5 (252; 54.8\%).

\section{Psychological Distress Prevalence}

The overall prevalence of severe psychological distress was $30.7 \%(N=161)$. Additionally, $25.6 \%$ of participants reported having moderate distress $(N=134)$, providing an overall prevalence of moderate to severe psychological distress of $56.3 \%$ $(N=295)$.

In a review of the associations between demographic characteristics and level of psychological distress (see Table 2), a significant association was found between females and severe psychological distress $(p<0.001)$. Moreover, family income was significantly associated with severe psychological distress in the extreme lower and upper groups (5000-10,000 SR and above 20,000 SR; $p=0.013$ and 0.016 , respectively).

\section{Perceived Stigma Towards Psychological Health Problems, Fear of Discrimination, and Privacy Breaches}

Participants' perceptions of self-stigma were relatively low, and $70.2 \%$ (277 of 524) of participants disagreed or strongly disagreed that it is a sign of personal weakness or inadequacy to receive treatment for emotional or mental health problems. 
Table 2 Multivariate analysis of the association between demographic characteristics and level of psychological distress

\begin{tabular}{llll}
\hline & & \multicolumn{2}{l}{ Response severe stress } \\
\hline Covariate & Level & Multivariate & $p$ value \\
Gender & Female & $1.67(1.339,2.09)$ & $<0.001$ \\
Year & 2nd & $0.83(0.516,1.34)$ & 0.452 \\
& 3rd & $1.00(0.673,1.47)$ & 0.982 \\
& 4th & $1.03(0.646,1.63)$ & 0.911 \\
& 5th & $1.42(0.708,2.83)$ & 0.325 \\
Marital status & Married & $1.58(0.525,4.78)$ & 0.415 \\
& Single & $0.77(0.343,1.74)$ & 0.532 \\
Family income & $5000-10,000 \mathrm{SR}$ & $2.00(1.158,3.45)$ & 0.013 \\
& $>10,000-20,000 \mathrm{SR}$ & $0.86(0.568,1.32)$ & 0.498 \\
& $>20,000$ & $0.63(0.434,0.92)$ & 0.016 \\
GPAC & $4-4.74$ & $0.88(0.665,1.17)$ & 0.377 \\
& $4.75-5$ & $0.87(0.605,1.24)$ & 0.437 \\
Age & 1 year increase & $0.91(0.703,1.17)$ & 0.455 \\
\hline
\end{tabular}

The italicized values demonstrate statistical significance considering a 2 sided $p$ value $<0.05$

However, when it comes to social stigma, around half of study subjects agreed or strongly agreed that residency directors, supervisors, fellow students, and patients would negatively react if they were aware the student had or was on treatment for emotional or mental health problem $(161 ; 40.7 \%, 218$; $55.2 \%, 171 ; 43.3 \%, 2663 ; 66.6 \%)$. Participants, however, were not sure about confidentiality regarding emotional or mental health problems. A total of $50.4 \%$, neither agreed nor disagreed that mental health care provided to medical students by their school/affiliated institution is truly confidential (199 of 524$)$, or that deans $(44.3 \% ; 175)$ or residency program directors $(41 \%$; 162) could access their personal medical records if they wished to do so. However, 45\% (178 of 524) disagreed or strongly disagreed that if they sought treatment for an emotional or mental health problem, it might end up in their academic record. A similarly high percentage $(61.8 \%$; 244) agreed or strongly agreed that if they were to receive treatment for an emotional or mental health problem, they would hide it from people.

All ten items of stigma showed a statistically significant association with participants having moderate to severe psychological distress; therefore, a multiple logistic regression model was used to identify independent variables (see Table 3). Table 3 shows that in comparison with respondents with mild psychological distress, those with moderate to severe psychological distress were more likely to perceive stigma. For instance, participants with higher level of psychological distress were more likely to agree or strongly agree that it is a sign of personal weakness or inadequacy to receive treatment for emotional or mental health problems $(\mathrm{OR}=1.80 ; p=$
0.003). In addition, they agreed or strongly agreed that fellow students would see them in a less favorable way if they found out the participant had received treatment for emotional or mental health problems $(\mathrm{OR}=1.36 ; p=0.015)$. Furthermore, they disagreed or strongly disagreed that mental health care provided by their school/affiliated institution is truly confidential $(\mathrm{OR}=1.46 ; p=0.012)$.

\section{Discussion}

Mental and emotional disorders are known causes of reduced work and school performance; therefore, it is important that mental health issues are identified and treated early. In this study, the K6 was used to assess the emotional and mental health of medical students [23]. The overall prevalence of moderate to severe psychological distress was $56.3 \%$, which showed that the medical students who participated in our study experienced relatively high levels of psychological distress. Abdulghani et al. showed a similarly high prevalence of stress among medical students at King Saud University in 2011, reaching $63.8 \%$ [12]. This may be attributed to the similarity in the scale (Kessler 10) used in their study. A previous study performed by Al Saadi in 2017 among Syrian medical students at Damascus University showed that psychological distress was estimated to be $52.6 \%$ in that population [10]. In addition, a recent meta-analysis reviewed 77 studies, included in which were data from 62,728 medical students, and found the global prevalence of depression to be $28 \%$ [28]. Such a high prevalence of emotional disorders might be attributed to the stigmatization of mental illness and the fear of being exposed experienced by individuals with mental health disorders.

Our findings showed that females were more affected than males, which offered some confirmation for the previous analysis by Abdulghani measuring stress and its effects on 775 medical students at King Saud University [12]. Furthermore, Al Saadi showed that females were twice as likely to show symptoms of depression and anxiety as males in a population of Damascus University Syrian medical students [10].

In the current study, family income was identified as a risk factor for psychological distress. Medical students with low (5000-10,000 SR) or high family incomes (>20,000 SR) had a significant association with severe psychological distress. This factor was not either addressed in similar studies, or was considered, but did not show any significance [10, 12, 24]. For example, Al Saadi reported that personal income was more significantly related to psychological distress than family income among Syrian medical students [10].

In contrast to previously published studies [12, 13, 24], the current study showed no significant difference in distress levels among different stages of medical education. This was not in line with other studies that suggested different findings, 
Table 3 The association between stigma and moderate to severe psychological distress using multiple logistic regression model $\mathrm{OR}, \mathrm{CI}$, and $p$ value

\begin{tabular}{|c|c|c|c|}
\hline \multirow[b]{2}{*}{ Covariate } & \multirow[b]{2}{*}{ Level } & \multicolumn{2}{|c|}{ Response $=$ severe + moderate stress } \\
\hline & & Multivariate OR (95\% CI) & $p$ value \\
\hline Stigma1 & Strongly agree + agree & $1.80(1.221,2.66)$ & 0.003 \\
\hline Stigma2 & Strongly agree + agree & $0.97(0.758,1.25)$ & 0.824 \\
\hline Stigma3 & Strongly agree + agree & $1.02(0.789,1.32)$ & 0.868 \\
\hline Stigma4 & Strongly agree + agree & $1.36(1.061,1.75)$ & 0.015 \\
\hline Stigma5 & Strongly agree + agree & $1.05(0.831,1.33)$ & 0.673 \\
\hline Stigma6 & Strongly disagree + disagree & $1.46(1.089,1.97)$ & 0.012 \\
\hline Stigma7 & Strongly agree + agree & $1.08(0.798,1.45)$ & 0.631 \\
\hline Stigma8 & Strongly agree + agree & $1.20(0.893,1.61)$ & 0.228 \\
\hline Stigma9 & Strongly agree + agree & $1.23(0.925,1.64)$ & 0.155 \\
\hline Stigma10 & Strongly agree + agree & $1.23(0.986,1.53)$ & 0.067 \\
\hline
\end{tabular}

The italicized values demonstrate statistical significance considering a 2 sided $p$ value $<0.05$ and it was reported in Abdulghani study that levels of distress were highest among first-year students (78.7\%) in Saudi Arabia [12]. Additionally, in 2005, Dahlin studied 342 medical students at Karolinska Institute, Sweden, in their first, third and sixth years. Higher level of stress was observed in first year students compared to third and sixth. [29]. On the contrary, Shaikh and Saipanish reported higher level of stress among third- and fourth-year medical school students in Pakistan and Thailand. Such discrepancy could be attributed to the different scales used to measure distress in these studies [30, 31].

As for marital status, no significant association was observed in this study, which was anticipated, given the low percentage of participants who were married $(2.8 \%)$, compared with those who were single which is in line with the overall school demographics [32]. In contrast, a systematic review performed by Dyrbye in 2006 indicated that multiple studies showed lower stress rates among married students, relative to their single counterparts [28].

This questionnaire used in this study provided a description of the beliefs about stigma perceived by medical students reporting psychological distress, as well as whether these beliefs regarding emotional or mental health problems were affected by their current distress levels. The findings of this study indicated that perceived stigma can be distorted by current states of emotional or mental health. For example, participants with severe psychological distress had higher scores related to stigma, compared with those with a lower level of distress. This is in line with the research findings of Dyrbye and colleagues [24]. Perceived stigma and fears of being judged and privacy breaches were shown to a great extent in participants with moderate to severe psychological distress, unlike those with low psychological distress. This finding corresponds to that of Dyrbye and colleagues' multiinstitutional study, in which medical students with burnout more frequently expressed beliefs in mental illness stigmatization [24].

Medical school is a competitive environment for students, in which they try to be the best version of themselves. This could explain why a fair amount of those students who undergo psychological distress feel weak when seeking treatment. In comparison with participants with mild psychological distress, those with moderate to severe psychological distress were more likely to agree or strongly agree that it is a sign of personal weakness or inadequacy to receive treatment for emotional or mental health problems. These findings are similar to those from a study by Schwenk, in which most students with moderate to severe depression agreed that if they asked for help, they would be admitting to themselves that their coping skills are inadequate, or would be blamed by others [33].

A previous study reported that in two medical schools in the UK, fear of being stigmatized was one of the barriers preventing medical students from seeking help [34]. The high percentage of medical students who agreed that program directors, supervisors, fellow students, and even patients would change their attitude and thoughts towards them if they knew about their mental health issues may have created a sense of insecurity and increased their efforts to conceal whatever distress they were experiencing. In the current study, most participants preferred to hide their emotional and mental health problems and were not quite confident regarding the confidentiality of their medical records. In another cross-sectional study, $16 \%$ of students observed supervisors violating the privacy of personal information of other students with emotional issues, making it an actual reality, rather than a fear [24].

This study had some limitations. One limitation was the use of a self-report survey, which may have created a possible recall bias. In addition, due to the study design, causal relationships could not be investigated. Furthermore, although 
medical students in this study were from a nearly similar sample in terms of age and profession, other known medical and psychological problems which can create great psychological distress were not addressed in the survey.

In conclusion, medical students with moderate to severe psychological distress $(56.3 \%)$, who were mostly females (65.22\%), disclosed more concerns regarding mental health stigma, affirming that it is a sign of personal inadequacy to receive treatment for a psychological health problem, doubting the confidentiality of mental health care provided by their institution and fearing that fellow students would condescend if they found out they had received psychological treatment. Such opinions could cause emotional and cognitive impairment and physical health problems, and ultimately reduce the quality of care provided to patients if distress was unrecognized and untreated for several years. The study findings implicate the importance of educational emphasis on mental disorders as a physical illness rather than a mental weakness, in addition to the seriousness of patient confidentiality and its subsequent effect on psychologic distress level. Further research is needed to look into the actions causing these confidentiality concerns and fear of stigmatization to benefit future physicians and their patients.

Acknowledgments The authors thank all medical students who contributed and participated in this study.

This work was supported by King Saud University, Riyadh, Saudi Arabia and by the College of Medicine Research Center, Deanship of Scientific Research, King Saud University, Riyadh, Saudi Arabia.

\section{Compliance with ethical standards}

Conflict of interest On behalf of all authors, the corresponding author states that there is no conflict of interest.

Open Access This article is licensed under a Creative Commons Attribution 4.0 International License, which permits use, sharing, adaptation, distribution and reproduction in any medium or format, as long as you give appropriate credit to the original author(s) and the source, provide a link to the Creative Commons licence, and indicate if changes were made. The images or other third party material in this article are included in the article's Creative Commons licence, unless indicated otherwise in a credit line to the material. If material is not included in the article's Creative Commons licence and your intended use is not permitted by statutory regulation or exceeds the permitted use, you will need to obtain permission directly from the copyright holder. To view a copy of this licence, visit http://creativecommons.org/licenses/by/4.0/.

\section{References}

1. Drapeau A, Marchand A, Beaulieu-Prévost D. Epidemiology of psychological distress. In: LAbate L, editor. Mental illness - understanding, prediction and control. INTECH Open Access Publisher; 2012. pp. 106-34, Rijeka, Croatia.

2. Kirmayer L. Cultural variations in the response to psychiatric disorders and emotional distress. Soc Sci Med. 1989;29:327-39.
3. McEwen B, Sapolsky R. Stress and cognitive function. Curr Opin Neurobiol. 1995;5:205-16.

4. McLachlan K, Gale C. The effects of psychological distress and its interaction with socioeconomic position on risk of developing four chronic diseases. J Psychosom Res. 2018;109:79-85.

5. Singh G, Hankins M, Weinman JA. Does medical school cause health anxiety and worry in medical students? Med Educ. 2004;38:479-81.

6. Rosal MC, Ockene IS, Ockene JK, Barrett SV, Ma Y, Hebert JR. A longitudinal study of students' depression at one medical college. Acad Med. 1997;72:542-6.

7. Chittleborough C, Winefield H, Gill T, Koster C, Taylor A. Age differences in associations between psychological distress and chronic conditions. Int J Pub Health. 2010;56:71-80.

8. Gispert R, Rajmil L, Schiaffino A, Herdman M. Sociodemographic and health-related correlates of psychiatric distress in a general population. Soc Psychiatry Psychiatr Epidemiol. 2003;38:677-83.

9. Kuriyama S, Nakaya N, Ohmori-Matsuda K, Shimazu T, Kikuchi N, Kakizaki M, et al. Factors associated with psychological distress in a community-dwelling Japanese population: the Ohsaki Cohort 2006 Study. J Epidemiol. 2009;19:294-302.

10. Al Saadi T, Zaher Addeen S, Turk T, Abbas F, Alkhatib M. Psychological distress among medical students in conflicts: a cross-sectional study from Syria. BMC Med Educ. 2017;17:73.

11. Dyrbye L, Thomas M, Eacker A, Harper W, Massie F, Power DV, et al. Race, ethnicity, and medical student well-being in the United States. Arch Intern Med. 2007;167:2103.

12. Abdulghani H, AlKanhal A, Mahmoud E, Ponnamperuma G, Alfaris E. Stress and its effects on medical students: a crosssectional study at a college of medicine in Saudi Arabia. J Health Popul Nutr. 2011;29:518.

13. AlFaris E, Irfan F, Qureshi R, Naeem N, Alshomrani A, Ponnamperuma G, et al. Health professions' students have an alarming prevalence of depressive symptoms: exploration of the associated factors. BMC Med Educ. 2016;16:279.

14. D'Arcy C, Siddique C. Psychological distress among Canadian adolescents. Psychol Med. 1984;14:615.

15. Myklestad I, Røysamb E, Tambs K. Risk and protective factors for psychological distress among adolescents: a family study in the Nord-Trøndelag Health Study. Soc Psychiatry Psychiatr Epidemiol. 2011;47:771-82.

16. Paul C, Ayis S, Ebrahim S. Psychological distress, loneliness and disability in old age. Psychol Health Med. 2006;11:221-32.

17. Walters V, McDonough P, Strohschein L. The influence of work, household structure, and social, personal and material resources on gender differences in health: an analysis of the 1994 Canadian National Population Health Survey. Soc Sci Med. 2002;54:677-92.

18. Phongsavan P, Chey T, Bauman A, Brooks R, Silove D. Social capital, socio-economic status and psychological distress among Australian adults. Soc Sci Med. 2006;63:2546-61.

19. Jorm A, Windsor T, Dear K, Anstey K, Christensen H, Rodgers B. Age group differences in psychological distress: the role of psychosocial risk factors that vary with age. Psychol Med. 2005;35:1253.

20. Caron J, Liu A. Factors associated with psychological distress in the Canadian population: a comparison of low-income and non lowincome sub-groups. Community Ment Health J. 2010;47:318-30.

21. Byrne P. Stigma of mental illness and ways of diminishing it. Adv Psychiatr Treat. 2000;6(1):65-72.

22. Komiya N, Good G, Sherrod N. Emotional openness as a predictor of college students' attitudes toward seeking psychological help. J Couns Psychol. 2000;471:138-43.

23. Kessler RC, Barker PR, Colpe LJ, Epstein JF, Gfroerer JC, Hiripi E, Howes MJ, Normand SL, Manderscheid RW, Walters EE, Zaslavsky AM. K-6 Distress Scale - Self Administered. In: Measurement instrument database for the social sciences. 2019. 
http://www.midss.org/content/k-6-distress-scale-self-administered. Accessed 18 May 2019.

24. Dyrbye L, Eacker A, Durning S, Brazeau C, Moutier C, Massie F, et al. The impact of stigma and personal experiences on the helpseeking behaviors of medical students with burnout. Acad Med. 2015;90:961-9.

25. Kessler RC, Barker PR, Colpe LJ, Epstein JF, Gfroerer JC, Hiripi E, et al. Screening for serious mental illness in the general population. Arch Gen Psychiatry. 2003;60:184-9.

26. Prochaska J, Sung H, Max W, Shi Y, Ong M. Validity study of the K6 scale as a measure of moderate mental distress based on mental health treatment need and utilization. INT J METH PSYCH RES. 2012;21(2):88-97.

27. Link BG, Yang LH, Phelan JC, Collins PY. Measuring mental illness stigma. Schizophr Bull. 2004;30:511-41.

28. Dyrbye L, Thomas M, Shanafelt T. Systematic review of depression, anxiety, and other indicators of psychological distress among U.S. and Canadian medical students. Acad Med. 2006;81:354-73.

29. Dahlin M, Joneborg N, Runeson B. Stress and depression among medical students: a cross-sectional study. Med Educ. 2005;39:594604.
30. Shaikh BT, Kahloon A, Kazmi M, Khalid H, Nawaz K, Khan N, et al. Students, stress and coping strategies: a case of Pakistani medical school. Educ Health (Abingdon). 2004;17(3):346-53.

31. Saipanish R. Stress among medical students in a Thai medical school. Med Teach. 2003;25(5):502-6.

32. AlFaris E, Irfan F, Ponnamperuma G, Jamal A, Van der Vleuten C, Al Maflehi N, et al. The pattern of social media use and its association with academic performance among medical students. Med Teach. 2018. https://doi.org/10.1080/0142159X.2018.1465536.

33. Schwenk TL, Davis L, Wimsatt LA. Depression, stigma, and suicidal ideation in medical students. JAMA. 2010;304:1181-90.

34. Chew-Graham C, Rogers A, Yassin N. 'I wouldn't want it on my CV or their records;: medical students' experiences of help-seeking for mental health problems. Med Educ. 2003;37:873-80.

Publisher's Note Springer Nature remains neutral with regard to jurisdictional claims in published maps and institutional affiliations. 